\title{
Breast feeding and The Sustainable Development agenda
}

\author{
Shingirai Miranda Katsinde, Sunitha Chandrasekhar Srinivas
}

Faculty of Pharmacy, Rhodes University, P.O Box 94, Grahamstown, South Africa, 6139

\section{ABSTRACT}

Breast feeding and exclusive breastfeeding practices are essential for infant and young child growth and development. The advantages of breastfeeding and exclusive breastfeeding contribute to the sustainable development as a core practice which not only affects children, but also adults and the world at large.

Key words: breastfeeding, exclusive breastfeeding, sustainable development goals, global agenda, infant feeding

\section{INTRODUCTION}

Adequate and appropriate feeding practices are crucial for the optimal growth and development of infants and young children. Breastfeeding has been identified by the United Nations Children's Fund and the World Health Organisation as the single most effective and affordable feeding practice that should be adopted for good infant health and improved survival. ${ }^{1,2}$ Evidence suggests that breastfeeding alone can improve the chances of survival of a new-born by $44 \%$ if initiated within the first hour after birth. Unfortunately, recent global statistics show that only $43 \%$ of new-borns were breastfed within the first hour of birth, thereby increasing negative consequences to the infants. ${ }^{3,4}$

The survival of infants and children especially under the age of five, is an urgent matter that requires attention, and has been on the global agenda since the Alma-Ata Declaration of 1978.5 Noting that the 'health for all' goals that were set in 1978 at the Alma-Ata Declaration were not going to be met, the United Nations member states met at the Millennium Summit in 2000, and established the Millennium Development Goals (MDGs). Eight MDGs were formulated, and these were meant to address the imbalances in the social determinants of health. Of the MDGs, four are health related - with MDG 4 targeted at reducing child mortality: MDG 4 Target 4. A: Reduce by two-thirds, between 1990 and 2015, the under-five mortality rate. ${ }^{6,7}$ The WHO made recommendations that, to achieve MDG 4, preventable child deaths should be avoided with costeffective and sustainable interventions, such as breast feeding. ${ }^{8}$ The 2015 deadline for the MDGs passed, and again the targets for reducing infant and child mortality were not achieved. World leaders adopted the 2030 Agenda for sustainable development in 2015, which comprises 17 goals ranging from ending poverty, reducing hunger, improving gender equality, promoting sustainable economic growth, promoting health and well-being and reducing all forms of violence and related deaths everywhere.

\section{SDGs two and three}

Of the 17 SDGs, two are directly linked to breastfeeding:

DOI: 10.5530/ijopp.9.3.2

Address for

correspondence:

Shingirai M Katsinde, 1247 Shashi View Bindura Zimbabwe

Phone no:+263 772773144 E-mail :smkatsinde@gmail.com

Sustainable Development Goal 2 - End hunger, achieve food security and improved nutrition and promote sustainable agriculture. The second SDG aims at ending hunger and improving nutrition globally. One of the most disconcerting facts about nutrition worldwide is that poor nutrition results in the deaths of

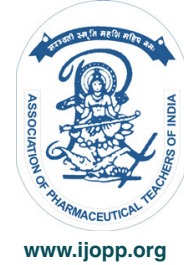


about $45 \%$ of the worlds under five children. The few survivors from this age group become the part of the 795 million people who are malnourished globally. SDG 2 targets include ending hunger especially amongst the vulnerable and the poor and ending all forms of nutrition especially stunting and wasting of children under the age of five years. ${ }^{9}$

Sustainable Development Goal 3 -Ensure healthy lives and promote well-being for all at all ages. This SDG focuses on reducing child and maternal deaths, as well as improving the health for all people worldwide through targeting conditions such as HIV/AIDS, non-communicable diseases and preventable child deaths. Progress has been made worldwide in the reduction of underfive mortality, maternal mortality and the provision of medicines in an attempt to reduce HIV/AIDS induced mortality - but still more can be done to improve. This goal incorporated MDGs 4 and 5, which were aimed at improving maternal and child health but both targets were not achieved. ${ }^{9,10}$

\section{Where do breastfeeding and exclusive breastfeeding fit in?}

Exclusive breast feeding practices have enhanced short and long term effects on the survival of children. ${ }^{1}$ Exclusive breastfeeding is when a child is given breast milk only, without any additional food, liquids or water.,11 The provision of only breast milk for the first six months of life is recommended by WHO as sufficient to provide all the nutrients for an infant. ${ }^{12,13}$ The provision of alternative foods within the first six months, or the addition of complimentary foods to an infant's diet, exposes them to possible diseases such as diarrhoea and respiratory infections. ${ }^{1,12,14}$ Babies who are not exclusively breastfed are more likely suffer from respiratory diseases, ear infections, dental caries, juvenile diabetes, and bacteraemia. ${ }^{15-17}$ Studies show that breastfed babies are protected from recurred occurrences of diarrhoea and dehydration - which are major contributors to infant and young child mortality globally. ${ }^{17,18}$ Infants are also protected against non-communicable diseases such as diabetes, which will not only improve the health of infants, but could substantially contribute to a decrease in infant and young child mortality. ${ }^{11}$

Improvement of maternal health compliments child health, due to the prime responsibility of child care being that of the mother. ${ }^{8}$ The targets of achieving SDGs 2 and 3 to improve nutrition and secure healthy lives for all starts with the first 1000 days of a child's life - which commences with breast feeding within the first hour of birth, and exclusive breast feeding for the first six months of life, as a primer for a healthier life. Exclusive breast feeding contributes to improving nutrition for infants for the first six months of life, and, if adopted correctly, with on-demand feeding can reduce malnutrition, stunting and wasting of infants and young children, making it possible to achieve these goals by $2030 .{ }^{9,10,19}$

Not with standing that breast feeding is not highlighted as part of any of the targets within any of the SDGs, it is a core infant feeding practice which substantively contributes to SGDs 2, 3.,10 Promoting exclusive breast feeding in a culturally appropriate manner enhances the chances of the acceptance of information, and possibly adoption of the practice by mothers. ${ }^{20,21}$ If mothers practice breast feeding exclusively, then they are less prone to post-partum depression, osteoporosis, ovarian, and breast cancers. The mother will also bond with her baby, which fosters a positive attitude and environment within which a mother will be living. This in turn will promote good health and wellbeing for the mother. ${ }^{17}$ in the long-term, adopting exclusive breast feeding practices will result in a reduction in maternal mortality due to improved health and wellbeing.

\section{CONCLUSION}

Breastfeeding and exclusive breast feeding have numerous benefits, and these are not only for the breast feeding mother, or the breastfed baby, but, as core to achieving global goals, it is a necessity that exclusive breast feeding and breast feeding should be promoted. This does not only apply to low income countries, but to middle and high income countries too, since the WHO reports that every country in the world has nutrition problems: be it obesity, malnutrition, or vitamin deficiencies. ${ }^{22}$ Increasing breast feeding practices improves nutrition for not only infants and young children, but for everyone, which is a positive step towards improving nutrition, ending hunger, promoting health well-being and healthy lives for all globally.

\section{ACKNOWLEDGEMENT}

Sincere gratitude to St Mary's Development and Care Centre and the Ubunye Foundation; the Department of Health Bhisho, Eastern Cape Province South Africa - for granting us access to the primary health care clinics. We also would like to extend out most sincere gratitude to the Rhodes University Community Engagement Office (Ms D. Hornby) and the Faculty of Pharmacy for the support during this study. This work is supported by: (1) Rhodes University Sandisa Imbewu Funding awarded to Prof. Srinivas and Ms Hornby. (2) Graça Machel and Canon Collins Trusts for the Graça Machel Scholarship awarded to Ms Katsinde. 


\section{CONFLICT OF INTERESTS}

The authors declare that they have no financial or personal relationship(s) which may have inappropriately influenced writing this paper.

\section{REFERENCES}

1. World Health Organisation. Exclusive breastfeeding [Internet]. World Health Organisation. 2015 [cited 2015 Mar 3]. Available from: http://www.who.int/ nutrition/topics/exclusive_breastfeeding/en/

2. United Nation Children's Fund. Breastfeeding [Internet]. UNICEF. 2015 [cited 2015 Jun 13]. Available from: http://www.unicef.org/nutrition/index_24824.html

3. South Africa: Policy turnaround on breastfeeding [Internet]. IRINnews. 2014 [cited 2015 Mar 3]. Available from: http://www.irinnews.org/report/93600/southafrica-policy-turnaround-on-breastfeeding

4. United Nation Children's Fund. Committing to child survival. A promise renewed. [Internet]. United Nations Children's Fund; 2014 [cited 2015 Jun 13]. Available from: http://data.unicef.org/corecode/uploads/document6/uploaded_ pdfs/corecode/APR-2014-170ct14-web_194.pdf

5. Declaration of Alma-Ata. In Alma-Ata, USSR: World Health Organisation; 1978 [cited 2015 Mar 8]. Available from: http://www.who.int/publications/almaata_ declaration_en.pdf

6. Millennium Development Goals [Internet]. UNDP in South Africa. 2012 [cited 2015 Jun 13]. Available from: http://www.za.undp.org/content/south_africa/en/ home/mdgoverview.html

7. Progress for Children. Beyond averages: learning from the MDGs [Internet] UNICEF; 2015 [cited 2015 Jul 16]. Available from: http://www.unicef.org/ publications/files/Progress_for_Children_No._11_22June15.pdf

8. MDG 4: reduce child mortality [Internet]. World Health Organisation. 2015 [cited 2015 Jul 1]. Available from: http://www.who.int/topics/millennium_ development_goals/child_mortality/en/

9. United Nations. Sustainable Development Goals [Internet]. Sustainable Development Knowledge Platform. 2015 [cited 2016 Jan 4]. Available from: https://sustainabledevelopment.un.org/?menu=1300\#

10. United Nations. Millennium Development Goals Report - 2015 [Internet]. United Nations; 2015 [cited 2015 Jul 12]. Available from: http://www.undp.org/content/ dam/undp/library/MDG/english/UNDP_MDG_Report_2015.pdf
11. Kramer M, Kakuma R. Optimal duration of exclusive breastfeeding. Cochrane Database Syst Rev. 2009;(1).

12. World Health Organisation. Ten facts on breastfeeding [Internet]. World Health Organisation. 2015 [cited 2015 Mar 3]. Available from: http://www.who.int/ features/factfiles/breastfeeding/en/

13. Department of Health. South Africa Infant and Young Child feeding Policy 2013 [Internet]. Department of Health South Africa; 2013 [cited 2015 May 14]. Available from: http://www.kznhealth.gov.za/Nutrition/Infant_and_young_child_ feeding_policy.pdf

14. World Health Organisation. Complementary feeding [Internet]. World Health Organisation. 2015 [cited 2015 Mar 3]. Available from: http://www.who.int/ nutrition/topics/complementary_feeding/en/

15. Breastfeeding: achieving the new normal. The Lancet. 201630;387(10017):404.

16. Black RE, Allen LH, Bhutta ZA, Caulfield LE, de Onis M, Ezzati M, et al. Maternal and child undernutrition: global and regional exposures and health consequences. The Lancet. 2008;19;371(9608):243-60.

17. World Health Organisation, United Nation Children's Fund. Breastfeeding Counselling: A Training Course [Internet]. World Health Organisation/United Nations Children's Fund; 1993 [cited 2015 Jun 17]. Available from: http://www. who.int/maternal_child_adolescent/documents/pdfs/bc_participants_manual.pdf

18. Statistics South Africa. Mortality and causes of death in South Africa, 2013: Findings from death notification [Internet]. Statistics South Africa; 2014 [cited 2015 Jun 28]. Available from: http://www.statssa.gov.za/publications/P03093/ P030932013.pdf

19. World Health Organisation. Breastfeeding [Internet]. World Health Organisation. 2015 [cited 2015 Mar 25]. Available from: http://www.who.int/ topics/breastfeeding/en/

20. Kakute PN, Ngum J, Mitchell P, Kroll KA, Forgwei GW, Ngwang LK, et al. Cultural barriers to exclusive breastfeeding by mothers in a rural area of Cameroon, Africa. J Midwifery Women's Health. 2005;50(4):324-8. http:// dx.doi.org/10.1016/j.jmwh.2005.01.005; PMid:15973270.

21. Kreuter MW, McClure SM. The Role of Culture in Health Communication. Annu Rev Public Health. 2004;25(1):439-55. http://dx.doi.org/10.1146/annurev. publhealth.25.101802.123000 ; PMid:15015929.

22. United Nation Children's Fund. The state of the world's children 2015 : Executive Summary [Internet]. United Nations Children's Fund; 2014 [cited 2015 Jul 16]. Available from: http://data.unicef.org/corecode/uploads/document6/uploaded_ pdfs/corecode/SOWC_2015_Summary_and_Tables_210.pdf 